\title{
A Survey of Materials for Additive Manufacturing
}

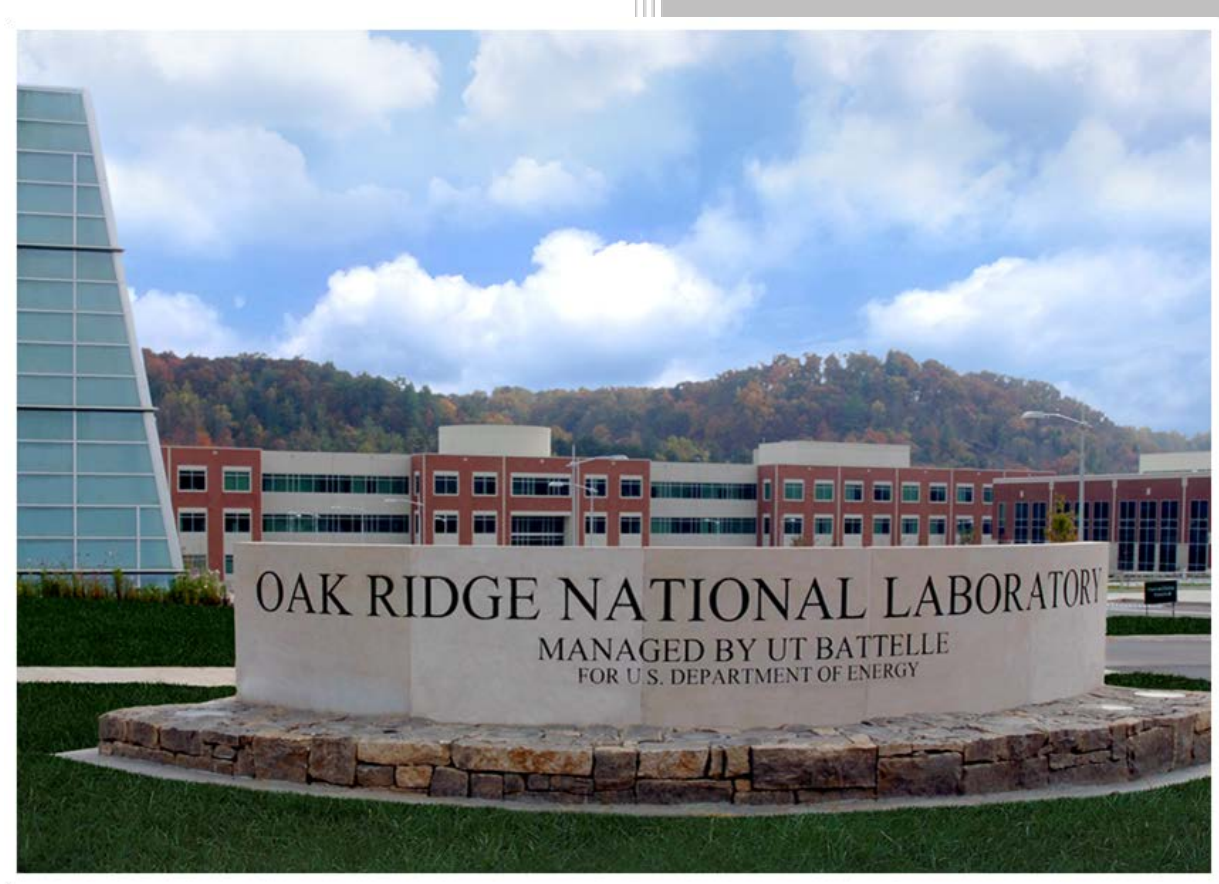

R. J. Belles

R. E. Hale

T. J. Harrison

M. D. Muhlheim

W. P. Poore

N. R. Taylor, The Ohio State

University

Approved for public release.

Distribution is unlimited.

June 2018 


\section{DOCUMENT AVAILABILITY}

Reports produced after January 1, 1996, are generally available free via US Department of Energy (DOE) SciTech Connect.

Website www.osti.gov

Reports produced before January 1, 1996, may be purchased by members of the public from the following source:

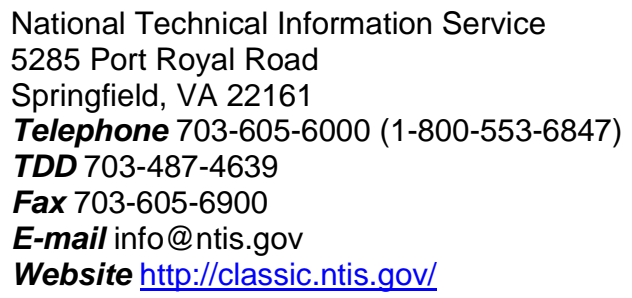

Reports are available to DOE employees, DOE contractors, Energy Technology Data Exchange representatives, and International Nuclear Information System representatives from the following source:

Office of Scientific and Technical Information

PO Box 62

Oak Ridge, TN 37831

Telephone 865-576-8401

Fax 865-576-5728

E-mail reports@osti.gov

Website http://www.osti.gov/contact.html

This report was prepared as an account of work sponsored by an agency of the United States Government. Neither the United States Government nor any agency thereof, nor any of their employees, makes any warranty, express or implied, or assumes any legal liability or responsibility for the accuracy, completeness, or usefulness of any information, apparatus, product, or process disclosed, or represents that its use would not infringe privately owned rights. Reference herein to any specific commercial product, process, or service by trade name, trademark, manufacturer, or otherwise, does not necessarily constitute or imply its endorsement, recommendation, or favoring by the United States Government or any agency thereof. The views and opinions of authors expressed herein do not necessarily state or reflect those of the United States Government or any agency thereof. 
Reactor and Nuclear Systems Division

\title{
A SURVEY OF MATERIALS FOR ADDITIVE MANUFACTURING
}

\author{
R. J. Belles \\ R. E. Hale \\ T. J. Harrison \\ M. D. Muhlheim \\ W. P. Poore \\ N. R. Taylor, The Ohio State University
}

Date: June 2018

Prepared by

OAK RIDGE NATIONAL LABORATORY

Oak Ridge, TN 37831-6283

managed by

UT-BATTELLE, LLC

for the

US DEPARTMENT OF ENERGY

under contract DE-AC05-00OR22725 



\section{CONTENTS}

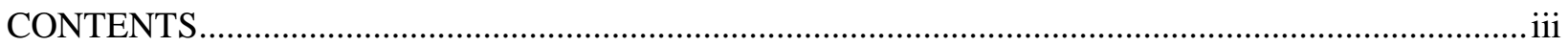

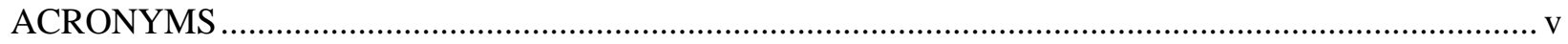

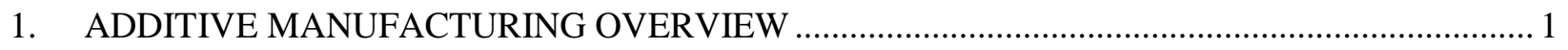

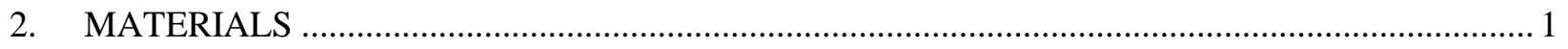

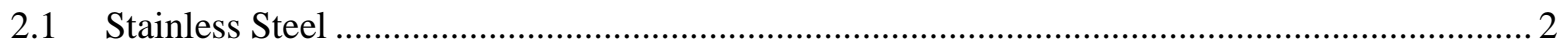

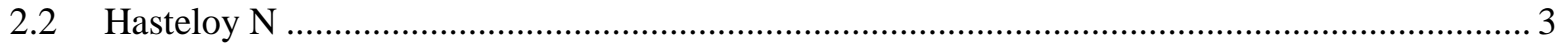

2.3 Common Metallic Alloys Used in Additive Manufacturing.................................................. 3

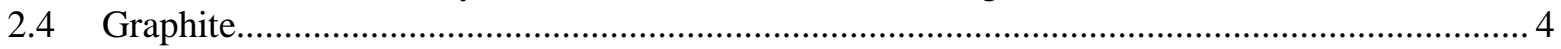

2.5 Additive Manufacturing Considerations and Concerns .......................................................... 5

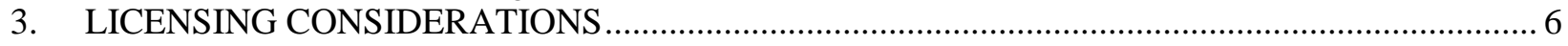

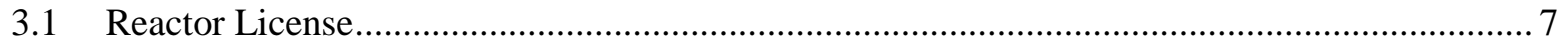

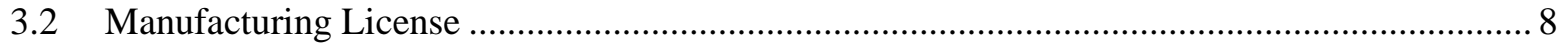

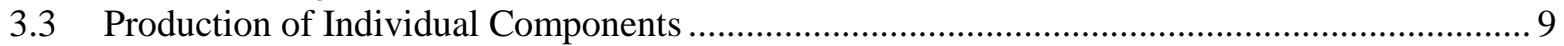

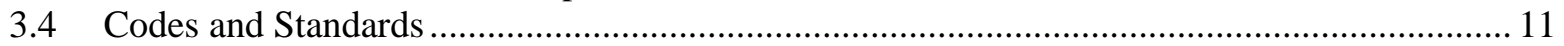

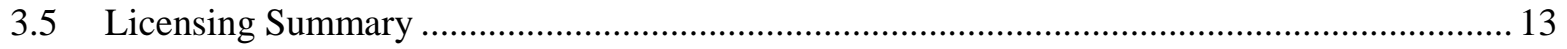





\section{ACRONYMS}

$\begin{array}{ll}\text { AEC } & \text { Atomic Energy Commission } \\ \text { AM } & \text { Additive manufacturing } \\ \text { AMSC } & \text { Additive Manufacturing Standardization Collaborative } \\ \text { ANSI } & \text { American National Standards Institute } \\ \text { ASME } & \text { American Society of Mechanical Engineers } \\ \text { ASTM } & \text { American Society for Testing and Materials } \\ \text { BPVC } & \text { Boiler and Pressure Vessel Code } \\ \text { BWR } & \text { boiling water reactor } \\ \text { COL } & \text { combined license } \\ \text { DOE } & \text { US Department of Energy } \\ \text { DoD } & \text { US Department of Defense } \\ \text { FAA } & \text { Federal Aviation Administration } \\ \text { FSAR } & \text { final safety analysis report } \\ \text { LWR } & \text { light water reactor } \\ \text { Non-LWR } & \text { non-light water reactor } \\ \text { NRC } & \text { US Nuclear Regulatory Commission } \\ \text { PWR } & \text { pressurized water reactor } \\ \text { RG } & \text { regulatory guide } \\ \text { SAE } & \text { Society for Automotive Engineers } \\ \text { SDO } & \text { standards developing organization } \\ \text { SPR } & \text { special purpose reactor } \\ \text { SSC } & \text { systems, structures, and components }\end{array}$





\section{ADDITIVE MANUFACTURING OVERVIEW}

Very small special purpose reactors (SPRs) are under consideration by various entities for remote installations and communities. This type of plug-and-go resource requires inherently positive safety attributes and sound design. Such reactors may be transportable with fresh fuel to serve as a complete power "battery" and they may even be transportable on short notice after initial use. SPRs could eliminate costly and in some cases dangerous fossil fuel deliveries. Small passively safe reactors could be operated remotely by an offsite operations crew. While use cases for such reactors are currently under development, advanced manufacturing processes should be considered to support reactor economics.

Additive manufacturing (AM) techniques are beginning to provide benefits to numerous industries in terms of reducing cost, weight, waste, etc. The aerospace, defense, medical, and automobile industries are prime examples of industries benefiting from AM. Smaller applications of this technology are beginning to appear in the nuclear industry. SPRs, especially micro-size reactors, may benefit from using AM to produce systems, structures, and components (SSCs) for nuclear power reactors. This may include production of the fuel, the SSCs in the nuclear island, and other potential applications. For very smallscale reactors, a large portion of the power plant could be produced in a factory using AM techniques and then transported to a fixed or temporary location.

AM offers numerous benefits to the reactor industry. It provides the ability to produce geometries that are difficult or costly to produce with conventional (subtractive machining) methods. AM also provides the ability to produce multiple layers of materials, such as coatings, cladding, or gradients of materials. AM produces components quickly and with minimal waste, and it offers significant reductions in time and infrastructure associated with spare parts management. The potential for improved component capabilities and performance, shorter parts production time, and reduced supply side infrastructure is significant.

This report provides a survey of known reactor materials used in a variety of advanced reactors, excluding fuel materials. Use of AM in the nuclear industry is in its early stages, so this report attempts to provide some information on the current state of relevant codes, standards, and regulatory requirements for using AM in producing an SPR. Specific reactor use cases and overviews of various reactor types are not included in this report.

\section{MATERIALS}

As the commercial use of reactors in the United States has grown, the corresponding size of the reactors has also grown to take advantage of economies of scale. To a point, this approach was successful in reducing cost per kilowatt. However, the economics of these large reactor projects has approached a level that is no longer viable for utilities to continue to consider under current market conditions. The recent cancellation of the Summer nuclear power plant expansion and the financial struggles to complete expansion of the Vogtle nuclear power plant illustrate this trend.

Likewise, there are many markets for nuclear reactors, some of which support more small-scale energy supply applications. As noted in the overview, small and remote power applications for clean, reliable nuclear power plants are under consideration. However, the economy of scale still applies. Therefore, SPR vendors must be innovative in their approach to reactor operation and construction to reduce cost while still providing for the health and safety of the public and protection of the environment. AM presents what may be a possible path to successful construction. Innovation is also required in areas not addressed herein. These areas include staffing, operation, maintenance, control, and communication. 
Numerous reactor concepts can be considered for the SPR project, including liquid-metal-cooled reactors, gas-cooled reactors, molten salt-cooled reactors, molten salt-fueled reactors, and heat pipe reactors. These reactors use many of the same types of materials as full-scale reactors, but specific applications and alloys may differ. A broad discussion of some of the most common or noted materials used in reactor applications is provided in this section.

Designers and developers of SPRs operating at high temperatures who expect to deploy them in the short term to produce power will be required to use code-qualified materials in their construction, or they must propose alternative material qualification programs. Presently there are several code-qualified stainlesssteel alloys with high-temperature applications, and others are being considered. It will be necessary to qualify components produced with AM processes to ensure that they retain attributes equivalent to conventionally made components having the same function.

\subsection{STAINLESS STEEL}

Stainless steel is the most common material found in various reactor applications: it is resistant to corrosion caused by interaction between its alloying components and the reactor environment. All stainless steels are comprised of at least 12 percent chromium.

The two most common austenitic stainless-steel grades are Alloys 304 and 316. Both alloys (H version) are currently American Society of Mechanical Engineers (ASME) Boiler and Pressure Vessel Code (BPVC) qualified Division 5 high-temperature materials. Alloy 304 is the most widely used industrial austenitic stainless steel. Alloy 304 has nuclear reactor applications. By comparison, Alloy 316 has an increased nickel content and includes $2 \%$ molybdenum, providing increased corrosion resistance, particularly against chlorides and chlorinated solutions like sea water and de-icing salts. Therefore, Alloy 316 stainless steel is particularly desirable for applications in which salt exposure is an issue. In addition to better corrosion resistance, Alloy 316 provides excellent elevated temperature tensile, creep, and stressrupture strengths, as well as outstanding formability and weldability_-making it is a good choice for reactor material. Increased nickel content and the inclusion of molybdenum makes Alloy 316 stainless steel a bit more costly to produce than Alloy $304 .{ }^{1}$

Incoloy $800 \mathrm{H}$ is another ASME BPVC-qualified Division 5 high-temperature material available for hightemperature reactor applications. Alloy $800 \mathrm{H}$ is a nickel-iron-chromium material that resists oxidation, carburization, and other high temperature corrosion. Other ASME BPVC Division 5 qualified materials include 2.25Cr-1Mo ferritic steel and grade 91 martensitic steel (9Cr-1Mo-V enhanced).

Inconel Alloy 617 is a high-temperature, corrosion-resistant steel under consideration for use in reactor designs; it is in the final phase of ASME qualification. Alloy 617 has a high nickel and chromium content, making it resistant to reducing and oxidizing media.

Another austenitic stainless steel being developed for reactor applications is Alloy 709; it is currently undergoing ASME Code qualification. Alloy 709 has shown superior high-temperature creep strength as compared to current generation high-temperature structural materials like Alloy 316 stainless steel and grade 91 martensitic steel.

\footnotetext{
${ }^{1}$ Nickel Development Institute, “High-Temperature Characteristics of Stainless Steels,” A Designers’ Handbook Series Number 9004.
} 


\subsection{HASTELLOY N}

HASTELLOY ${ }^{\circledR} \mathrm{N}$ alloy (UNS N10003) is a nickel-based alloy that was developed at Oak Ridge National Laboratory (ORNL) as a container material for molten fluoride salts. ${ }^{2}$ Alloy $\mathrm{N}$ is composed of $71 \%$ nickel, $7 \%$ chromium, and $16 \%$ molybdenum. It demonstrated good oxidation resistance to hot fluoride salts in the temperature range of $1300-1600^{\circ} \mathrm{F}\left(704-871^{\circ} \mathrm{C}\right)$ during operation in the Molten Salt Reactor Experiment (MSRE). In MSRE tests, corrosion attack on Alloy $\mathrm{N}$ in molten fluoride salts at temperatures up to $1300^{\circ} \mathrm{F}\left(704^{\circ} \mathrm{C}\right)$, was less than one mil per year.

HASTELLOY ${ }^{\circledR} \mathrm{N}$ alloy has good oxidation resistance in air. It shows promise for continuous operations at temperatures up to $1800^{\circ} \mathrm{F}\left(982^{\circ} \mathrm{C}\right)$. Intermittent use at temperatures up to $1900^{\circ} \mathrm{F}\left(1038^{\circ} \mathrm{C}\right)$ may also be possible. Alloy $\mathrm{N}$ has good weldability and can be readily forged. The hot working range is between $1600-2150^{\circ} \mathrm{F}\left(871-1177^{\circ} \mathrm{C}\right)$. It has been successfully extruded and further processed into high-quality seamless or manufactured as welded and drawn tubing. ${ }^{2}$

Alloy $\mathrm{N}$ is a principle molten salt reactor (MSR) high-temperature material, although further testing with chloride salts is necessary. High-temperature code qualification for alloy $\mathrm{N}$ is also necessary.

Table 1. Comparison of selected alloy properties

\begin{tabular}{|c|c|c|c|c|}
\hline Property & Alloy 304 & Alloy 316 & Alloy $800 \mathrm{H}$ & Alloy N \\
\hline Tensile strength (ultimate psi) & 73,200 & 84,100 & 77,000 & 115,100 \\
\hline Tensile strength (yield psi) & 31,200 & 42,100 & 29,000 & 45,500 \\
\hline Density (lb/in $\left.{ }^{3}\right)$ & .289 & .289 & .287 & .320 \\
\hline $\begin{array}{l}\text { Thermal conductivity @ } 212^{\circ} \mathrm{F} \\
\left(\text { BTU-in } / \mathrm{hr}^{-} \mathrm{ft}^{2}{ }^{\circ} \mathrm{F}\right)\end{array}$ & $112 @ 212{ }^{\circ} \mathrm{F}$ & $113 @ 212{ }^{\circ} \mathrm{F}$ & $127 @ 212^{\circ} \mathrm{F}$ & $114 @ 800^{\circ} \mathrm{F}$ \\
\hline $\begin{array}{l}\text { Specific heat capacity } \\
\left(\mathrm{BTU} / \mathrm{lb}-{ }^{\circ} \mathrm{F}\left[32-212^{\circ} \mathrm{F}\right]\right)\end{array}$ & 0.12 & 0.12 & 0.11 & \\
\hline Melting point $\left({ }^{\circ} \mathrm{F}\right)$ & $2,550-2,650$ & $2,500-2,550$ & $2,475-2,525$ & $2,375-2,550$ \\
\hline
\end{tabular}

\subsection{COMMON METALLIC ALLOYS USED IN ADDITIVE MANUFACTURING}

Research has been conducted on properties of select AM metals, and their properties have been compared to conventionally produced counterparts. The properties observed vary widely among the AM materials because there is a wide range of build processes, heat sources, and processing parameters that can impact the mechanical properties of the metal. The list of commonly tested AM metals produced using powder bed fusion and direct energy deposition processes includes the following: ${ }^{3}$

- $\quad$ SS 304

- $\quad$ SS 304L

- $\quad$ SS 316

- $\quad$ SS 316L

- Inconel 625

- $\quad$ Inconel 718

\footnotetext{
${ }^{2}$ Haynes International, http://www.haynesintl.com/alloys/alloy-portfolio_/Corrosion-resistant-Alloys/hastelloy-n-alloy/principlefeatures

${ }^{3}$ T. DebRoy, et al., “Additive Manufacturing of Metallic Components - Process, Structure, and Properties,” Progress in Materials Science 92, pp 112-234, 2018.
} 
- $\quad$ Ti-6Al-4V

- ALSi10Mg

- AlSi12

Testing by Westinghouse has shown that unirradiated and irradiated AM Alloy 316L samples exceed American Society for Testing and Materials (ASTM) 316L specifications for tensile properties. The AM stainless steel displayed a greater yield strength, ultimate tensile strength, and hardness than conventionally processed SS 316L samples. However, the samples did exhibit a lower ductility. ${ }^{4}$ For most other metals, no relationship could be determined, as AM processes varied too much and produced varying results.

It is important to note that alloys 304 304L, 316, and 316L are designations for wrought alloys, which are ductile enough to be worked hot or cold during fabrication. However, AM is not a wrought process-it is a melting and solidification process. AM metals are more like cast-metal alloys. Metal casting is characterized by molten metal flowing into a mold by gravity or into a die by high pressure to create a shape. Therefore, the melting and solidification that occurs during AM is like casting. There is no deformation processing in typical AM. Cast Alloys CF3, CF3M, CF8, and CF8M are the approximate equivalent of wrought Alloys 304 304L, 316, and 316L. ${ }^{5}$

A range of compositions is allowed in the specifications for wrought alloys and for cast alloys. In the case of wrought alloys, both 316 and 304 are nonmagnetic because they are produced in the range of composition where delta ferrite is avoided. In the case of cast alloys CF8 and CF8M, they are somewhat magnetic due to the presence of delta ferrite that is purposely enabled by compositional changes to avoid hot tearing. Likewise, AM builds made from these families of materials are somewhat magnetic due to the presence of delta ferrite. Therefore, while vendors seek to emulate Alloys 304 and 316 using AM for reactor applications, Alloys 304 and 316, by definition, are not AM products. ${ }^{6}$

\subsection{GRAPHITE}

Graphite is widely used in reactor applications as a moderator for thermal reactors, a reflector for fast reactors, and as part of the fuel matrix itself. Graphite can be manufactured in a high purity form without neutron-absorbing materials, and it can withstand high heat. The melting point of reactor-grade graphite is $6,600^{\circ} \mathrm{F}$, well above the melting points for the steels shown in Table 1. Reactor-grade graphite is used extensively in gas-cooled reactors. It is also compatible with fluoride and chloride salts in MSRs.

Nuclear-grade graphite should have high density, high thermal conductivity, and high strength, and it should also have a low coefficient of thermal expansion. Table 2 indicates some typical properties of reactor-grade graphite.

\footnotetext{
${ }^{4}$ Paula Freyer, Westinghouse, NRC Public Meeting "Laboratory Testing and Evaluation of Unirradiated and Neutron Irradiated Additively Manufactured Alloys, November 28-29, 2017.

${ }^{5}$ Wrought equivalents from ASTM A 781/A 781M, Table X2.1.

${ }^{6}$ A presentation by Westinghouse on its AM test program referred to the tested alloys as AM Alloys. This served to differentiate wrought Alloy 316L from AM Alloy 316L. The AM-tested alloy was probably similar to cast Alloy CF8M.
} 
Table 2. Typical reactor-grade graphite properties

\begin{tabular}{lc}
\hline Property & $\begin{array}{c}\text { Nuclear } \\
\text { graphite }\end{array}$ \\
\hline Tensile strength (ultimate psi) & 3,625 \\
Density $\left(\mathrm{lb} / \mathrm{in}^{3}\right)$ & .065 \\
Thermal conductivity (BTU-in/hr- $\left.\mathrm{ft}^{2}{ }^{\circ}{ }^{\circ} \mathrm{F}\right)$ & 541 \\
Melting point $\left({ }^{\circ} \mathrm{F}\right)$ & 6,600 \\
\hline
\end{tabular}

\subsection{ADDITIVE MANUFACTURING CONSIDERATIONS AND CONCERNS}

A recent journal article observes the positive aspects of AM for industry ${ }^{7}$ :

Additive manufacturing (AM) processes build three-dimensional (3D) parts by progressively adding thin layers of materials guided by a digital model. This unique feature allows production of complex or customized parts directly from the design without the need for expensive tooling or forms such as punches, dies or casting molds and reduces the need for many conventional processing steps. Intricate parts, true to their design can be made in one-step without the limitations of conventional processing methods (e.g. straight cuts, round holes) or commercial shapes (e.g., sheet, tubing). In addition, a significant reduction in the part count can be realized by eliminating or reducing the need to assemble multiple components. Furthermore, parts can be produced on demand, reducing the inventory of spares and decreasing lead time for critical or obsolete replacement components.

However, the journal article author offers the following caveat regarding the use of AM:

While certain applications have reached technology readiness levels of fully certified production, most have done so through brute force certification of each individual part type, material and process. A more thorough understanding of the feedstock materials, processes, structures, properties and performance are desirable to produce defect-free, structurally-sound and reliable AM parts.

This is the challenge for the nuclear industry. AM offers the possibility of component cost reduction and inventory reduction. However, proving the equivalency of each AM component to its conventionally produced counterpart is difficult.

As noted at a recent US Nuclear Regulatory Commission (NRC) workshop, ${ }^{8}$ component quality is a concern for items produced using AM processes. The AM build process must consider the critical component parameters, stresses, surface roughness, and density. AM techniques also include post-build activities that may include densification, annealing, and surface processing. The final AM component properties and structural performance must be comparable to what can be produced using traditional manufacturing processes. This includes allowances for inspection of part and defect characteristics.

\footnotetext{
${ }^{7}$ T. DebRoy, et al., Additive Manufacturing of Metallic Components - Process, Structure, and Properties, Progress in Materials Science 92, pp 112-234, 2018.

${ }^{8}$ NRC Public Meeting, “Additive Manufacturing for Reactor Materials and Components,” November 28-29, 2017.
} 
NRC workshop participants from the National Institute of Standards and Technology ${ }^{9}$ and from the aerospace industry ${ }^{10}$ made the following observations regarding reactor components manufactured using AM processes:

- Limited material types exist

- Components may have unknown or nonuniform properties

- There is a lack of process repeatability

- Consensus protocols and/or test data for qualification and certification do not currently exist

- $\quad$ Surface finish is insufficient

- There is a lack of AM standards

- Improved nondestructive examination methods for complex defects and part geometry are needed

- Specification of the amount of process rigor is required for different parts with different applications

- Ability to meet location-specific properties is needed

- There are problems with inspectability/surface quality of difficult-to-access areas (can components be used with as-produced surfaces?)

- Must not increase component fatigue failure rate

One reactor designer ${ }^{11}$ indicated that the nuclear industry has more difficulty than other industries incorporating new materials and designs into a power plant, including AM processes. The reasons for this include the cost of validation, limited facilities, and a reluctance to innovate. Component validation against traditional materials and manufacturing processes is probably the greatest hurdle. Currently, AM methods can result in components having increased performance uncertainty, which is undesirable in the nuclear industry.

Another reactor designer ${ }^{12}$ observed that $\mathrm{AM}$ is a disruptive technology because it displaces an established technology and transforms an industry, or it is a groundbreaking product that creates a completely new industry. This reactor designer indicated that they are initially engaging in the AM arena with tooling. The designer continues to investigate the best options for building with AM processes.

In a news release, BWX Technologies, Inc., headquartered in Lynchburg, Virginia, announced that it has teamed with ORNL and will use its unique capabilities and facilities to develop implementation of AM processes for the fabrication of nuclear components and subcomponents. It is expected that the AM process will yield suitable material structure and strength that can be accepted by the national code organizations and the regulators. This is a positive step for implementing AM processes in the nuclear industry. Some of the licensing considerations are discussed in Section 3.

\section{LICENSING CONSIDERATIONS}

SPR vendors and the entities that are considering using SPRs to be manufactured in large part using AM techniques must be aware of the regulatory issues that may be associated with this technology. Depending on the end user, SPRs may be regulated by the NRC, the US Department of Energy (DOE), or the US

\footnotetext{
${ }^{9}$ Paul Witherell, NIST, NRC Public Meeting, "Informatics in AM Qualification: Incorporating Databases, Simulation, and Analysis,” November 29, 2017.

${ }^{10}$ Dr. Michael Gorelik, FAA, NRC Public Meeting, "Regulatory Considerations for AM Qualification and Status of FAA AM Roadmap,” November 28-29, 2017.

${ }^{11}$ Myles Connor, GE-Hitachi, NRC Public Meeting, “Evaluation of Additively Manufactured Materials for Nuclear Plant Components,” November 28-29, 2017.

12 Zesus Karoutas, Westinghouse, NRC Public Meeting, “The ’Big Picture’ Vision for AM in the Nuclear Industry,” November 28-29, 2017.
} 
Department of Defense (DoD). The health and safety of the public must be considered. This section explores some of the licensing considerations for AM relative to reactor materials and components.

\subsection{REACTOR LICENSE}

The NRC licenses all commercially owned nuclear power plants that produce electricity or provide other energy services in the United States, no matter where they may be sited. ${ }^{13}$ After the initial license is granted, the license may be amended, renewed, transferred, or otherwise modified, depending on activities that affect the reactor during its operating life. The NRC also licenses research and test reactors used for research, testing, and training. Applicants may apply for a construction permit and subsequent operating license under 10 CFR 50. Or an applicant may apply for a combined license (COL) under 10 CFR 52, Licenses, Certifications, and Approvals for Nuclear Power Plants.

As noted in 10 CFR 50.22, Licenses for Commercial and Industrial Facilities, an NRC class 103 reactor license (from the Atomic Energy Act) will be issued to an applicant qualified to transfer or receive in interstate commerce, manufacture, produce, transfer, acquire, possess, or use a production or utilization facility for industrial or commercial purposes. Any production or utilization facility which is also useful in the conduct of research and development activities is deemed to be for industrial or commercial purposes if more than 50 percent of the annual cost of owning and operating the facility is devoted to the (1) production of materials, products, or energy for sale or commercial distribution, or (2) to the sale of services other than research and development or education or training. The standard review plan for lightwater reactor (LWR) applications is found in NUREG-0800, Standard Review Plan for the Review of Safety Analysis Reports for Nuclear Power Plants: LWR Edition.

Likewise, 10 CFR 50.21, Licenses for Medical Therapy and Research and Development Facilities, notes that an NRC class 104 license will be issued to an applicant qualified to transfer or receive in interstate commerce, manufacture, produce, transfer, acquire, possess, or use:

(a) A utilization facility for use in medical therapy, or

(b) A production or utilization facility, which is useful in the conduct of research and development activities which is not a facility of the type specified in 10 CFR 50.22.

The standard review plan for test reactor applications is found in NUREG-1537, Guidelines for Preparing and Reviewing Applications for the Licensing of Non-Power Reactors.

Reactors located on DOE sites can be licensed by the NRC. In fact, any reactors located on DOE sites that are operated for demonstrating the suitability of a commercial application must be licensed by the NRC. ${ }^{13}$ Alternatively, DOE production, test, and research reactors can be managed under 10 CFR 830, Nuclear Safety Management. DOE nuclear facilities are classified by hazard categories 1, 2, 3, and below category 3.10 CFR 830 defines these hazard categories as shown in Table 3.

Table 3. DOE Nuclear Facility Hazard Categories

\begin{tabular}{ll}
\hline DOE nuclear facility category & Potential consequences \\
\hline 1 & Significant offsite consequences \\
2 & Significant onsite consequences beyond localized consequences \\
3 & Only local significant consequences \\
Below Category 3 & Only consequences less than identified above \\
\hline
\end{tabular}

${ }^{13}$ The Energy Reorganization Act of 1974 (P.L. 93-438) established the NRC and provided this regulatory authority. 
Guidance for hazard classification is provided by DOE Standard 1027-92, Hazard Categorization and Accident Analysis Techniques for Compliance with DOE Order 5480.23, Nuclear Safety Analysis Reports, Table A.1, "Thresholds for Radionuclides.” DOE reactor facilities are divided into two of the listed hazard categories. DOE Order 5480.30, Nuclear Reactor Safety Design Criteria, defines category A reactor facilities as "those production, test, and research reactors designated by DOE based on power level (e.g., design thermal power rating of 20 megawatts steady state and higher), potential fission product inventory, and experimental capability.” Category A reactors are categorized in nuclear facility hazard category 1 as defined in Table 3. Category B reactor facilities are "those test and research reactors designated by DOE based on power level (e.g., design thermal power rating of less than 20 megawatts steady state), potential fission product inventory, and experimental capability.” Category B reactors are categorized in nuclear facility hazard category 2 as defined in Table 3.

10 CFR 830 is applicable to DOE nuclear facility hazard categories 1, 2, and 3. In Table 2, this requirement indicates that DOE reactor operators (contractors) may prepare the documented safety analyses using NRC Regulatory Guide 1.70, Standard Format and Content of Safety Analysis Reports for Nuclear Power Plants (LWR Edition), or a successor document. Regulatory Guide (RG) 1.70 was last revised in November 1978. The most recent NRC regulatory review of RG 1.70 was performed in September 2014. The 2014 review noted that since the development of RG 1.70, there have been several updates to RGs, as well as sections of NUREG 0800, in support of new reactor licensing. Therefore, RG 1.70 is no longer being exclusively used by applicants for licensing new reactors. RG 1.206, Combined License Applications for Nuclear Power Plants (LWR Edition), was developed to provide guidance to applicants who planned to use the 10 CFR Part 52 process to reference an early site permit, a design certification, both, or neither, in a COL application. RG 1.206 was based on the existing guidance provided in RG 1.70. Because RG 1.70 and 1.206 reference 10 CFR 50 and subsequently 10 CFR 52, this guidance would only apply to DOE Category A reactors based on the power rating. DOE Category B reactors could follow the guidance of NUREG-1537 for test and research reactors.

DoD generally conducts nuclear plant safety reviews under the DOE process, which is site specific. However, exemptions may apply, such as the Naval Nuclear Propulsion program exemption noted in 10 CFR 830 per Public Law 106-65.

Reactor SSCs must meet the requirements in ASME BPVC Section III per 10 CFR 50.55a. Therefore, AM must be incorporated into Section III for NRC licensing purposes. Some AM concerns and licensing processes are noted in the following discussion.

\subsection{MANUFACTURING LICENSE}

An SPR supplier can consider obtaining an NRC manufacturing license under 10 CFR 52.167, Issuance of Manufacturing License, to produce an SPR. Among other requirements, this regulation stipulates "there is reasonable assurance that the reactor(s) will be manufactured, and can be transported, incorporated into a nuclear power plant, and operated in conformity with the manufacturing license, the provision of the [Atomic Energy] Act, and the Commission's regulations.” The manufacturing license could include AM techniques as authorized by the NRC in granting the license.

The manufacturing license includes tight parameters on use as discussed in 10 CFR 52.167.b, which requires that each manufacturing license specify:

- Technical specifications for operation of the manufactured reactor;

- Site parameters and design characteristics for the manufactured reactor; and 
- Interface requirements to be met by the site-specific elements of the facility — such as the service water intake structure and the ultimate heat sink - that are not within the scope of the manufactured reactor.

Under the manufacturing license, a reactor can only be delivered to a fixed site where a licensee holds a construction permit or a COL as stated in 10 CFR 52.167.c.1: "A holder of a manufacturing license may not transport or allow to be removed from the place of manufacture the manufactured reactor except to the site of a licensee. The licensee construction permit or combined license must authorize the construction of a nuclear power facility using the manufactured reactor(s).” This would preclude ${ }^{14}$ the use of an NRC manufacturing license to produce and deliver an SPR that is intended to be mobile as might be required by DoD or other entities. NRC regulations are not structured to facilitate licensing of a mobile reactor, though this could be explored.

\subsection{PRODUCTION OF INDIVIDUAL COMPONENTS}

To install or fabricate equipment used in a licensed nuclear facility, the fabricator or assembler must possess an $\mathrm{N}$ stamp issued and certified by ASME. To obtaining an $\mathrm{N}$ stamp, an organization must have a certified quality assurance program in accordance with Section III of the ASME BPVC for components installed in nuclear facilities. ASME has played a vital role in supporting the nuclear power industry since the first publication of the ASME BPVC, Section III, "Rules for Construction of Nuclear Facility Components" in 1963. The implementation of the ASME Nuclear Certification Program in 1968 has only strengthened that support.

An N-type certificate of authorization issued by ASME signifies that the certificate holder has undergone a rigorous survey to verify the adequacy and effective implementation of the quality assurance program. The N-type certificates of authorization allow certificate holders to certify and stamp newly constructed components, parts, and appurtenances used at a nuclear facility with the certification mark in accordance with Section III of the ASME BPVC. ASME issues six different N-type certificates and an owner's certificate that authorizes the following scope of activities:

- $\mathrm{N}$ : Vessels, pumps, valves, piping systems, storage tanks, core support structures, concrete containments, and transport packaging

- NA: Field installation and shop assembly of all items

- NPT: Parts, appurtenances, welded tubular products, and piping subassemblies

- NS: Supports

- NV: Pressure relief valves

- N3: Transportation containments and storage containments

- OWN: Nuclear power plant owner

AM replacement components may be an option for reactors that have already been constructed. Individual components that are manufactured using AM techniques can be introduced into a reactor plant through one of three NRC-accepted methods: ${ }^{15} 10$ CFR 50, Appendix A, General Design Criteria 1, Quality Standards and Records, and 10 CFR 50, Appendix B, Quality Assurance Criteria for Nuclear Power Plants, provide for NRC nuclear quality assurance requirements. The three methods are described below.

In the first method, a manufacturer can provide the NRC staff with a topical report that outlines the AM process and associated analysis. This report should document that the part is the equivalent of a part

\footnotetext{
${ }^{14}$ Unless an exemption was sought and granted by the NRC

${ }^{15}$ Allen Hiser, NRC, NRC Public Meeting, "Topics of Interest for Additive Manufacturing of Reactor Materials and

Components,” November 29, 2017
} 
manufactured by traditional methods already in use in a plant. The manufacturer would obtain a safety evaluation from the NRC staff. An affirmative staff safety evaluation would allow an applicant to use the AM part within the specific guidelines of the topical report and the associated safety evaluation.

To implement the second method, an applicant could seek a license amendment to use an AM component in place of a component produced by traditional methods. This would include an analysis similar to that described in the first option and would likely require support from a manufacturer.

In the third method, an applicant could use the process available under 10 CFR 50.59, Changes, Tests and Experiments to make like-for-like changes in the facility as described in the final safety analysis report (FSAR), revise the procedures as described in the FSAR, and conduct tests or experiments not described in the FSAR-- without obtaining a license amendment only if:

1. A change to the technical specifications incorporated in the license is not required, and

2. The change, test, or experiment does not meet any of the criteria below.

A licensee shall obtain a license amendment prior to implementing a proposed change, test, or experiment if the change, test, or experiment would:

(i) Result in more than a minimal increase in the frequency of occurrence of an accident previously evaluated in the FSAR;

(ii) Result in more than a minimal increase in the likelihood of occurrence of a malfunction of an SSC important to safety previously evaluated in the FSAR;

(iii) Result in more than a minimal increase in the consequences of an accident previously evaluated in the FSAR;

(iv) Result in more than a minimal increase in the consequences of a malfunction of an SSC important to safety previously evaluated in the FSAR;

(v) Create a possibility for an accident of a different type than any previously evaluated in the FSAR;

(vi) Create a possibility for a malfunction of an SSC important to safety with a different result than any previously evaluated in the FSAR;

(vii) Result in a design basis limit for a fission product barrier as described in the FSAR being exceeded or altered; or

(viii) Result in a departure from a method of evaluation described in the FSAR used in establishing the design bases or in the safety analyses.

The most likely issue that an AM component would be required to prove using the 10 CFR 50.59 change process is item ii in the list above, a "minimal increase in the likelihood of occurrence of a malfunction of an SCC important to safety previously evaluated in the FSAR.” This includes all non-safety-related SSCs the failure of which could adversely impact functionality of safety-related SSCs.

All NRC processes listed above require quality assurance per 10 CFR 50, Appendix B, which requires that every applicant for a construction permit is required by the provisions of 10 CFR 50.34 to include in its preliminary safety analysis report a description of the quality assurance program to be applied to the design, fabrication, construction, and testing of the structures, systems, and components of the facility. Similar requirements are listed for COL applications. Appendix B includes topics such as procurement document control; control of purchased material, equipment and services; identification and control of materials, parts, and components; control of special processes; and inspection

DOE Standard 1104-2009, Review and Approval of Nuclear Facility Safety Basis and Safety Design Basis Documents, provides for the DOE review of SSC safety basis. DOE Order 414.1D, Quality Assurance, and its associated guidance document DOE G 414.1-2B, Quality Assurance Program Guide, provide for DOE nuclear quality assurance requirements. 


\subsection{CODES AND STANDARDS}

The NRC endorses certain consensus codes and standards for use in nuclear power plant design and construction. This endorsement is typically implemented through 10 CFR 50.55a, Codes and Standards, ${ }^{16}$ which lists codes and standards that can be incorporated by reference into reactor design and construction documentation. Other documents, such as regulatory guides, can also be used to endorse certain consensus standards in part or in whole. The difficulty with 10 CFR 50.55a is that it endorses ASME BPVC Section III, Rules for Construction of Nuclear Facility Components, which outlines the appropriate material selection, design, fabrication, installation, examination, and testing of components for boiling water reactor (BWR) and pressurized water reactor (PWR) systems and components. The hightemperature materials needed by many advanced SPRs are not included nor are any high-temperature material code cases included. AM processes are not included under any of the manufacturing processes for any material. Current stainless steels governed by ASME BPVC Section III are wrought alloys. AM materials are more closely aligned with cast alloys, which will complicate any effort to govern the manufacture of AM materials under ASME BPVC Section III. 10 CFR 50.55a(z) does provide for the use of alternatives to codes and standards for applicants if the applicant can show an acceptable level of safety and quality. The BPVC also has provisions for allowing new materials.

Establishing a code case is a possibility for qualifying AM reactor materials and components. These are documents submitted in the form of a question and a response, and they are used to "represent alternatives or additions to existing Code requirements.” The BPVC notes that a common application for a code case is to "permit use of a new material for Code construction" or "gain experience with new materials or alternative requirements prior to incorporation directly into the Code." A code case could be submitted to provide an AM process for materials that were already qualified using conventional manufacturing techniques. The appropriate ASTM standards, along with data showing the comparison of AM materials with standard production methods, would be cited as evidence to show that AM materials perform as well as already qualified materials. However, a code case must be subjected to a review by an ASME BPVC committee and then be accepted by the NRC. Therefore, establishing a code case is not a simple or quick process.

Nonetheless, adequate codes and standards for AM processes are lacking. At a recent NRC workshop, ${ }^{17}$ many participants voiced concerns regarding the need for the development of codes and standards to govern the use of AM. Several participants at the workshop reported on progress in this regard.

ASTM International, an international standards developing organization (SDO) that develops consensus and improves performance in manufacturing and materials, reported on their organization's progress in developing technical AM standards. More specifically, the America Makes \& American National Standards Institute (ANSI) Additive Manufacturing Standardization Collaborative (AMSC) works to coordinate and accelerate the development of AM standards. AMSC and ASTM International initially identified 89 gaps in AM standards, including topics with high, medium, and low priority. In subsequent reviews, 2 of these initial gaps were closed, and 5 were withdrawn. However, 11 new gaps were identified, leaving 93 gaps to be analyzed, tracked, and resolved. ${ }^{18}$ AMSC and ASTM International have AM technical standards under review or approved in the areas of terminology, data formats, qualification guidance, system performance and reliability, test protocols, design guides, test methods, test artifacts, safety, inspection methods, and others. Specific standards in these areas are developed for three major areas of AM: (1) feedstock materials, (2) process/equipment, and (3) finished parts.

\footnotetext{
1610 CFR 50.55a, Codes and standards

${ }^{17}$ NRC Public Meeting, “Additive Manufacturing for Reactor Materials and Components,” November 28-29, 2017.

${ }^{18}$ America Makes \& ANSI AMSC, Standardization Roadmap for Additive Manufacturing, Version 2.0, April 6, 2018.
} 
ASTM standards can be used to perform the necessary testing of mechanical properties because they include testing for tension, compression, bearing, bend, Young's modulus, hardness, fatigue, fracture toughness and crack growth. The testing procedures for these properties are the same as those for the standard manufactured metals of the same types. Current ASTM standards include:

- $\quad$ ASTM F3122-14 - Standard Guide for Evaluating Mechanical Properties of Metal Materials Made via Additive Manufacturing Processes

- $\quad$ ASTM F3049-14 - Standard Guide for Characterizing Properties of Metal Powders Used for Additive Manufacturing Processes

- $\quad$ ASTM F2792-10 - Standard Terminology for Additive Manufacturing Technologies

- ASTM F2971-13 - Standard Practice for Reporting Data for Test Specimens Prepared by Additive Manufacturing

- ISO/ASTM 52915-16 - Standard Specification for Additive Manufacturing File Format (AMF) Version 1.1

- ISO/ASTM 52901-16 - Standard Guide for Additive Manufacturing - General Principles Requirements for Purchased AM Parts

- $\quad$ ASTM F3056-14e1 - Standard Specification for Additive Manufacturing Nickel Alloy (UNS N06625) with Powder Bed Fusion

- $\quad$ ASTM F3055-14a - Standard Specification for Additive Manufacturing Nickel Alloy (UNS N07718) with Powder Bed Fusion

- ASTM F2924-14 - Standard Specification for Additive Manufacturing Titanium-6 Aluminum-4 Vanadium with Powder Bed Fusion

- $\quad$ ASTM F3184-16 - Standard Specification for Additive Manufacturing Stainless Steel Alloy (UNS S31603) with Powder Bed Fusion

- $\quad$ ASTM F2313-17 - Standard for Additive Manufacturing - Finished Part Properties - Standard Specification for Cobalt-28 Chromium-6 Molybdenum via Powder Bed Fusion

In addition to ASTM International, numerous SDOs are participating in the development of AM standards. The SDOs include:

- Association for the Advancement of Medical Instrumentation

- ASME

- American Welding Society

- Digital Imaging and Communications in Medicine

- Institute for Electrical and Electronics Engineers

- $\quad$ IPC - the Association Connecting Electronics Industries

- International Organization for Standardization

- Medical Imaging \& Technology Alliance

- Metal Powder Industries Federation

- MTConnect Institute

- National Electrical Manufacturers Association

- Society for Automotive Engineers (SAE) International

The NRC is supporting two ASME efforts to establish a technical baseline to develop a proposed BPVC standard or guideline addressing the pressure integrity governing the construction of pressure-retaining equipment by additive manufacturing processes for nuclear and nonnuclear applications. The ASME goal is to incorporate AM processes into the BPVC. ${ }^{19}$ This is significant for nuclear plant AM applications.

${ }^{19}$ David Rudland, NRC, NRC Public Meeting, “BPTCS/BNCS Special Committee on Use of Additive Manufacturing,” November 28-29, 2017. 
Addition of ASME Section III, Division 5 for high temperature materials to the BPVC took approximately 10 years. The NRC has not yet endorsed Division 5, even though it has been part of BPVC Section III for more than 5 years. Based on this experience, the goal to incorporate AM processes into the BPVC and the subsequent endorsement by the NRC are not likely to occur in the near future for use in nuclear applications.

\subsection{LICENSING SUMMARY}

SDOs have indicated that they have a focus on developing standards and guides for implementing AM. These processes are just beginning and will take time to mature. Similarly, reactor licensing through the NRC and reactor authorization through DOE have not established clear-cut processes to incorporate AM components in nuclear power plants. However, the most likely path to incorporate AM technology is to include AM in a consensus standard, followed by NRC endorsement in a regulatory guidance document. NRC is beginning to consider AM technology as evidenced by the recent 2-day workshop on the subject. Likewise, DOE maintains an Advanced Manufacturing Office. A DOE factsheet ${ }^{20}$ notes some advantages of AM, including lower energy intensity, less waste, reduced time to market, innovation, and agility. According to the factsheet, ongoing challenges include process control, tolerances, surface finish, and validation and demonstration. These and several other challenges were voiced during the 2-day NRC workshop. The surface finish is of particular concern based on the number of times this issue was mentioned. Surface finish affects vital component properties, including resistance to flow, corrosion, and wear. When intricate parts are produced using AM techniques, some surfaces may not be adequately finished due to inaccessibility.

On a positive note, NuScale expects their design to be well timed for implementing AM techniques. ${ }^{21}$ They have planned for codes, standards, and capabilities to align so that they can take advantage of progress in the AM industry. NuScale is fostering a close set of partners to serve as part of their supply chain; no bid list for individual plants is anticipated. NuScale's goal is to create a purpose-built factory to produce reactor modules. Other non-LWRs will be positioned even better for utilizing AM processes. Applications of AM technology to future reactors and the associated licensing issues should be explored further.

\footnotetext{
${ }^{20}$ DOE/EE-0776, Additive Manufacturing: Pursuing the Promise, August 2012.

${ }^{21}$ Steven Wolbert, NuScale, NRC Public Meeting, “Additive Manufacturing for Reactor Materials and Components,” November 28, 2017.
} 